Volume 30, 2020

http://journals.sfu.ca/cjsdw

\title{
Article
}

\section{Tooling up the Multi: Paying Attention to Digital Writing Projects at the Writing Centre}

Stephanie Bell

York University

Brian Hotson

Saint Mary's University

\section{Abstract}

With increasing regularity over the last decade, Canadian undergraduate students are being tasked with digital writing projects (DWPs), including wikis, blogs, video and audio essays, websites, and social media engagements. Currently, Canadian writing centres are silent about how DWPs are or might be supported within writing centre programming. To initiate the discussion, we asked our 2019 CWCA/ACCR conference workshop participants to consider ways of supporting a DWP in the writing centre. Our goal in the workshop, as well as in this paper, is to reflect on the ways writing centres are and can be supporting students working on digital writing projects. Workshop participants' questions reveal several areas of attention beyond additional technology, including resources, pedagogical approaches, and writing centre programming and spatial design. Using this paper as an extension of our workshop, we examine the literature on digital and multimodal writing (which is largely American). It is in this literature that we find implications for building writing centre supports, involving both programs and spaces that foster student efforts to recognize media/modal affordances, develop and engage in design thinking, and build self-efficacious beliefs.

Keywords: Student efficacy, digital writing projects, social justice, multimodality, writing centre 
Volume 30, 2020

http://journals.sfu.ca/cjsdw

\section{Introduction}

With increasing regularity over the last decade, Canadian undergraduate students have been tasked with producing digital writing projects (DWPs), which include wikis, blogs, video and audio essays, websites, social media engagements, online learning modules, and a proliferation of other multimodal DWPs. Currently, Canadian writing centre studies' literature is silent about how DWPs (Bell \& Hotson, forthcoming) are supported within writing centre programming, even if we are not seeing many DWPs in our current programming. We know what these projects are being assigned. Still, we are unable to find research or literature on tutoring digital writing projects, including conference presentations, in a Canadian context. Since the first Canadian Writing Centres Association/L'Association canadienne des centres de rédaction (CWCA/ACCR) independent conference in 2013, CWCA/ACCR conference programs ${ }^{1}$ show only three sessions addressing DWPs, with no mention of digital writing at all in the 2017 CWCA/ACCR CFP, the "Future of Writing Centres." The 2019 conference's "multiverse" theme included the interdisciplinary approach of multimodality, which was at the centre of our workshop on supporting DWPs in writing centres as well as the contexts that inform this article.

It appears that a conversation about DWPs is only beginning among Canadian writing centre professionals. There remains uncertainty about whether or to what extent DWPs fit within the purview of current writing centre programming, policies, and practices as well as the degree to which they merit attention given that the number of digital projects coming into our centres is unknown. However, this conversation is necessary because DWPs are being used to engage students in learning and meaning making across disciplines regardless of disciplinary connections to fields of artistic production where skills like film production, sound design, and/or visual communication are program outcomes. From an institution-wide survey of faculty at large Canadian universities, we are beginning to quantify and describe the digital writing being asked of undergraduates across disciplines, leading to the work of extending writing centre theory and pedagogy to this growing area of undergraduate writing. Our initial research (Hotson \& Bell, forthcoming) suggests that DWPs, from task and tools through production and publication, are fraught and multi-layered spaces of meaning making that are always socially unjust: racialized, gendered, colonial, and classist (Gonzales, Calarco, \& Lynch, 2018; Soja, 2009). In addition, DWPs call upon students to engage in a variety of sensory modes of meaning making and communicating that are not typically required of "traditional" academic genres,

\footnotetext{
${ }^{1}$ See CWCA/ACCR Archives https://cwcaaccr.com/archives/
} 
Volume 30, 2020

http://journals.sfu.ca/cjsdw

with their own grammars and styles (Bell, 2019, p. 29; Mills \& Doyle, 2019, p. 522). By opening space for less conventional discourses and modalities, these assignments offer student writers as much opportunity as they do risk. For instance, DWPs offer opportunities for students to engage in creative, playful, inventive writing where authenticity, difference, and multiplicity are often valued (See for example, Ambrose, et al, 2018, p. 57; Bell, 2017, p. 21; Kent-Drury, 1998, p. 401-402; Mills, Comber, \& Kelly, 2013, p. 22-23). At the same time, these assignments present the risk of unfamiliar processes, unknown expectations, experimental assessment strategies, corporate-owned production tools, and public venues/audiences (Bell \& Hotson, forthcoming).

Students will benefit from academic support designed to mitigate the many risks of DWPs and help students take advantage of the opportunities to learn and create that these projects offer. What do these supports entail in a writing centre context? To answer this question, we asked workshop participants at the 2019 CWCA/ACCR to consider ways of supporting an example DWP in the writing centre. Our goal in the workshop, as well as in this paper, is to reflect on the ways writing centres are, can, and could be supporting students who are working on DWPs. Questions that emerged during the workshop reveal several areas of attention beyond additional technology, including resources, pedagogical approaches, and writing centre programming design. Encouraged by this expansion of our understanding of relevant concerns, we spent the weeks following the conference using these issues as guides into the literature on digital writing pedagogy. In this paper, we report on the workshop and the literature that the workshop helped us gather in order to turn the Canadian writing centre community's attention to the ways DWPs might challenge our current programming, pedagogy, resources, and spatial configurations.

\section{Workshop: A Digital Writing Project at the Writing Centre}

The CWCA/ACCR conference workshop that we facilitated asked Canadian writing centre professionals to discuss writing centres' current and future support for students working on DWPs. We divided workshop participants into four small groups, each with a unique image of a writing centre tutoring space with differing configurations of furniture and technology (see Appendix A). With these images of tutoring spaces, we asked participants to consider how they might approach the hypothetical tutoring scenario, "Social Science 1000: Mid-term Assignment," involving a student-created podcast (see Appendix B). We asked group participants to develop strategies for tutoring Clare, a fictional, mature learner feeling anxious about the assignment, given the resources of their assigned tutoring 
Volume 30, 2020

http://journals.sfu.ca/cjsdw

spaces. Our goal was to facilitate a wide-ranging conversation not only about the design of the hypothetical assignment, but also about the design of writing centre programming and the spatial configuration that facilitates it.

\section{Social Science 1000: Mid-term Assignment}

In a 15-minute audio recording (.mp3) + written transcript posted to the course blog: Explain the concept, "ideology," by analyzing an advertisement (see list of approved ads).

1. Illustrate the ways capitalism operates on constructed notions of what's "normal, natural, and necessary."

2. Explain clearly enough to make these ideas understandable to a peer.

Have a clear thesis statement that answers a "so what" question. Have fun with it! Your goal is to make these ideas clear and compelling to a peer. Your podcast should be somewhere between formal and informal and can be creative.

Engage with two course readings and additional resources (popular or scholarly) to interrogate the advertisement's claims about the product.

[see Clare's draft in Appendix B]

The workshop plan reflected our observation that the design of writing centres, including space and technology, typically facilitates live in-person conversation between tutor and student in association with printed drafts or notes and assignment instructions. This is the sort of tutoring work described across writing centre websites from our survey of the 22 English-speaking Canadian universities listed in the QS World University Rankings for 2019 (QS Ranking 2019, 2020). This survey reveals just one program for tutoring "digital media” projects (Ryerson University) and two discrete mentions of digital writing (Ryerson University and University of Waterloo). The vast majority of writing centre websites describe support for academic essay-type writing assignments. Notably, nine of the 22 websites direct students to arrive for sessions with a hard copy of their draft or notes in hand, something difficult to do with prototypes of multimodal DWPs.

We captured notes of the workshop groups' discussions, which reflected initial tutoring impulses (what participants thought they might try) in this hypothetical tutoring scenario given the affordances and constraints of the tutoring spaces provided. Participants raised several issues important to the development of DWP support that the workshop group was unable to resolve during the session. Although workshop participants did not come to much resolution (which was not neces- 
Volume 30, 2020

http://journals.sfu.ca/cjsdw

sarily the intention of the workshop), the questions they formulated as they contemplated the challenges presented by the DWP are productive outputs of the session. These questions create a path forward for writing professionals in Canada to turn their attention to the ways digital writing projects might challenge our current programming, pedagogy, resources, and spatial configurations, all of which have been designed to support text-based genres of academic writing. We spent the weeks following the conference using these issues as guides into the literature on digital writing pedagogy. What follows are specific questions from workshop participants. The format of this paper will provide clarity and direction from the literature.

\section{Workshop participant questions about interpreting the assignment}

\section{On DWP assignment clarification}

- Would we reach out to the instructor for clarification? What do we do in the event that the instructor is not sure of their own expectations for the experimental assignment? Can we continue with the session without knowing much about the instructor's expectations?

- What does the request to "Have fun with it" mean? What might the student uptake of this direction be?

- What is the central issue that the tutor should tackle with Clare? Is there a central issue that will create a path forward for substantive revision?

\section{On genre}

- What type or genre of podcast is expected? Are there clear-cut genres of podcasts that we would benefit from classifying in a how-to resource for student writers? Does such a resource already exist?

- Is it possible for a podcast to be produced by a single person and/or in this timeframe? Is the assignment realistic?

\section{On scope}

- How can we determine the scope and parameters for a 15-minute-long podcast? What resources are available to help us with questions of length, scope, depth, and breadth?

\section{On DWP sources and citation}

- The assignment asks the student to engage with sources but does not provide information about citation style or how to apply it in an oral text. Are there resources for oral attribution 
Volume 30, 2020

http://journals.sfu.ca/cjsdw

styles in podcasting/oral scholarship?

These questions reveal that even though this hypothetical assignment is framed as an opportunity for students to "have fun," it describes a complex task that might be anxiety-producing for them. The instructor may not have fully considered their own expectations for issues of oral citation, genre, and scope. Will the instructor discover what they need to assess as they are grading? This ignorance of the complexities of "fun" alternative digital projects is noted as a trend by Horner, Selfe, and Lockridge (2015), who describe it as a "fetishization" marked by a dismissive attitude toward the intellectual rigour and labour of digital composition. When multimodal forms of communication and knowledge production are fetishized they are approached as fads, celebrated but ultimately dismissed as being outside of scholarly work.

This likely unconscious fetishization is possibly driven by assumptions about "digital natives," a term coined by Prensky (2001). The widespread belief that digital natives-those who grew up living with internet-connected devices - have an innate understanding of how digital tools operate and how to make the most of their functionalities, has been discredited (Bennett, Maton, \& Kervin, 2008; Helsper \& Eynon, 2010; Judd, 2018; Passanisi \& Peters, 2012). Helsper and Eynon's (2010) study of technology use among university students finds that the term digital native is a misnomer. In fact, "the opposite is true-contemporary society is a continuation of the past"; knowledge is not innate. They warn against belief in the abilities of "young 'techy' generations" propelling a harmful deterministic view that technology represents "the 'fix' or 'solution"' to many educational challenges, and they call for additional research on the ways that both "younger and older generations learn through, and engage with, technology" (p. 518). Such research may help mitigate the digital-native concept from contributing to notions of fetishization.

Unfortunately, the belief in digital natives persists despite Helsper and Eynon's decade-old findings that "little evidence to support many of the key claims made by Prensky and like-minded commentators" (Judd, 2018, p. 115). The misconception continues to drive assumptions that most students do not need support with digital writing tools or digital production, and, therefore, faculty and writing centre tutors do not need training to provide support to students. As writing centres include digital writing projects, an expectation by faculty may arise that centres do the work of teaching digital writing hardware and software. Inevitably, though, faculty and administrators will discover that many presumed "digital natives" do require such support. In fact, this perspective fetishizes yet another aspect of technology, namely its supposed neutrality and immateriality. When instructors do 
Volume 30, 2020

http://journals.sfu.ca/cjsdw

not offer tech support for these projects, their approach assumes that tools are not a meaningful part of the production or academic processes, as though engagement with these tools is outside of meaning making. Horner, Selfe, and Lockridge (2015) explain that the fetishization of digital writing exists along with the dismissal of the "actual labor of teaching [its] production" (p. 30). Ironically, writing specialists spend much of their energy countering these sorts of assumptions about writing itselfthe notion that writing is a neutral tool for capturing pre-determined content.

\section{Workshop participant questions about modifying established tutoring routines}

\section{On HOCs and LOCs?}

- What would we classify as higher-order (HOC) and lower-order concerns (LOC) in the context of a podcast?

- In what ways are the two sets of issues interrelated and interdependent in this context?

- Could it be helpful to focus on lower-order concerns in order to make the assignment more approachable, and lead Clare to some of the higher-order issues she would benefit from addressing?

- Is it possible that aspects of the oral performance, which contribute to the construction of the text's meaning, should be classified as higher order concerns?

- Does the multimodality of the assignment change the ways tutors should get at, categorize, prioritize "higher-order concerns"?

- How do we categorize (HOC vs LOC) questions about software and hardware?

- What are the benefits of bringing writing tutoring and software support together, potentially even when addressing HOCs?

Workshop participants noted that a key element of tutoring sessions is rapidly identifying LOCs and HOCs, and that Clare's assignment caused them to lose their footing when it comes to this routine task. This appears to be a useful revelation for writing tutors to have, as it can help them respond to Grutsch McKinney's (2009) call for evolving traditional tutoring approaches like reading aloud, looking beyond the text, and HOCs over LOCs to better accommodate twenty-first century texts (p. 49). This evolution involves responding to the modalities involved in multimodal texts, which will require that instructors consider not just visual, audio, and artistic elements of student texts, but their layer- 
Volume 30, 2020

http://journals.sfu.ca/cjsdw

ing and cumulative effects as they each contribute to the construction of typically "higher-order" concerns such as argument, structure, and (arguably in the case of multimodal texts) mood.

Workshop participants brainstormed multimodal tutoring strategies, the most prominent of which was storyboarding, to get students thinking about the narrative development of the podcast and using recording software to listen to podcast drafts to consider issues of tone, style, and audience engagement. Literature on multimodal consulting practices recommends these strategies, as well as the use of prototyping, mapping, and mocking up depending on the nature of the project (see Sabatino \& Fallon, 2019). Of course, troubleshooting technical issues remains a consulting activity when any sort of technology of production is intimately involved in a meaning making and communication process, and these issues are often outside writing tutors' expertise. The key is that writing centres are places where these tasks come together, where students and tutors move fluidly amidst interrelationships of facility with software, comfort with digital writing tools, and a grasp of digital literacies and rhetorical multimodal meaning-making practices. It is also a place to direct students to other support staff to answer questions that writing centres cannot answer. Whatever tutoring strategies are developed, though, students need resources that help them believe in their abilities to successfully rise to meet multimodal tasks while also recognizing the complexity of those tasks, which can involve integrating linguistic, visual, audio, gestural, and/or spatial modes of meaning making.

\section{On disrupting habits}

- How can we disrupt Clare's habits to move her out of essay mode and into this more "fun" oral genre?

- How does she use available hardware/software (computer/smartphones) to experience recording part of the script or its revisions and listening to it back?

When considering the podcasting assignment example, participants agreed that the hypothetical student Clare is trapped in essay-mode, a mode ingrained through years of training about "good" writing. To engage her in the podcast genre, writing centre tutors need to work against Clare's judgements of permissible and "good" academic writing, which may be a particularly onerous task if she is relatively unfamiliar with the podcast genre and/or if her instructor's expectations are ambiguous. Silver (2019) finds that students need to be pushed out of a "resistant' stance toward multimodal composition" (p. 221) - a stance in which students underestimate the deep textual and communicative shifts required in DWPs by reducing multimodality to artistic and technical know-how (p. 220-21). 
Volume 30, 2020

http://journals.sfu.ca/cjsdw

This resistance among student writers can limit what they learn and produce using multimodal resources. Sheppard (2009), reflecting on her own multimodal composing efforts, details the careful negotiation of consequential rhetorical decisions at the core of digital writing: "These are not neutral, value-free skills" (p. 30). Sheppard helps us to see that writing support for students working on DWPs should help students explore the "communicative affordances" (p. 128) of various media as well as the ways multiple modes can integrate to comprise a unified text and "understanding the technical capabilities and contexts of use for the target audience, and developing an interface and set of interactions that make a text usable and intuitive" (p. 128). Effective communication requires an identification of elements associated with a rhetorical situation. Students need to know the purpose of the assignment, as well as "the story they are trying to tell" and to be able to "succinctly summarize" their story for the audience (Sabatino \& Fallon, 2019). The audience, rhetorically, becomes part of the process of writing; as Lunsford and Ede (2009) write, "writers and audience merge and shift places" in digital writing, "...participating in both brief and extended collaboration, it is more obvious than ever that writers seldom, if ever, write alone" (p. 45).

Gonzales's (2015) study of multimodal composing practices suggests that not all students recognize the affordances of digital, multimodal composing, and that many need assistance in learning how to do so. Although her sample size is limited, she shows that L1 writers described using multimedia tools as ornamentation to add emphasis to their texts, to highlight what they articulate in surrounding text. In contrast, L2 writers in her sample were inclined to use the multi-representational affordances of different media to expand ideas not easily articulated in other forms; she explains, "L2 writers used multimodality to layer a multiplicity of meanings rather than to reiterate a specific idea." Students who orchestrate multimodal resources to create layers of meaning have what Silver (2019) describes as a "broadened" understanding of writing and composing in "nonalphabetic modes and media" and can be characterized as "rhetorically savvy multimodal writers" (p. 217). Silver observes that "robust multimodal writing development" (p. 244) leads not just to different multimodal composing practices, but also to an "expanded self-perception as a writer" that motivates those practices (p. 228). This shifted identity may prompt students (and other writers) to describe themselves as writers and designers or writer-designers.

The evolution of multimodal writing has, in fact, prompted composition scholars to use writer/designer split as a means of capturing the interdisciplinarity of multimodal discursive practices. Purdy (2014) traces the introduction of design thinking into composition theory as "a vocabulary for and a way of thinking about composing that is capacious and action oriented" (p. 635), and especially as 
Volume 30, 2020

http://journals.sfu.ca/cjsdw

writing becomes increasingly multimodal. Design thinking offers a means of approaching multimodal composing as a culture, attitude, and process. It helps writers to take on "wicked problems" of writing that "lack a single, knowable solution" or reliable method of production because they are radically "ambiguous, contingent, and recursive" (p. 613). It offers a resourceful, creative problem-solving mindset or "orientation toward engaging with the world" (p. 626-27). This mindset is particularly helpful for multimodal composing involving the use of multiple media to experiment with connections, combinations, approaches, and perspectives. Purdy explains that design thinking offers writing scholars and teachers a means of accepting that writing is an effort of meaning making that increasingly involves using "all available resources" (p. 632). Introducing students to design thinking offers them resources to engage in meaningful multimodal composition, wherein writers take advantage of the affordances of media and online environments/cultures to produce new meaning, to invent with and inside of their writing tools (Wargo, 2017, p. 4) through "chancy" play (Arroyo, 2011, p. 59-61), creative assemblage, and social engagement. Students need support in using digital writing tools and materials in these ways, so they are able not just to communicate differently, but to communicate different ideas for online audiences and in digital cultures.

\section{Workshop participant questions about attending to student self-efficacy}

\section{On the affective experience of production}

- What might be Clare's affective experience of this disruption in her habits and familiar ways of working, and how can we, as tutors, support her in that experience?

\section{On self-efficacy}

- How do we centre students in these tutoring strategies, so that the strategies encourage students to take ownership of the knowledge and revision decisions that emerge during (and after) the tutoring session?

Workshop participants noted that students might need support with the affective elements of these assignments given that they involve expanded expectations of writing and writerly development. Writing centre tutors are not counsellors, but they often find themselves discussing writing as a lived, emotion-laden experience with students. There is cause to believe that this will remain true for DWPs, which, whether intended or not, can be emotively challenging and engaging. Despite being 
Volume 30, 2020

http://journals.sfu.ca/cjsdw

cast as fun alternatives to traditional writing assignments, DWPs are not free of the pressures of performance and assessment; in fact, these pressures can be amplified by the relative unfamiliarity of the tasks and ambiguous expectations. Writing centres can play an important role in supporting students through heightened anxiety around DWPs, which is important because, as Bell (2019) finds, anxiety can play a role in limiting multimodal writing development described by Silver (2019). This tracks with research on the intersection of cognition and affect. McLeod (1991) notes that "cognition must be viewed in concert with affect" (p. 95), and offers the example of learned helplessness in children who do not attempt to problem-solve when they believe they will ultimately fail at the task (p. 101). Problem-solving, therefore, is not only a cognitive but also an affective set of skills. Understanding this is important particularly for multimodal digital writing projects because they, as observed by Bell (2019), can cause a "decentering of [the] certainty and comfort" (p. 60) that more familiar writing assignments provide students. Bell explains that this decentering can cause some students to feel more anxious than they usually feel about coursework and even resentful of the challenge presented by the assignment. Some students experience the challenge as an exciting journey filled with exciting experimental play, and for many students the finished product is something about which they are pleasantly surprised by and proud of. For many students, however, this decentering is experienced as disempowering, and as a threat rather than a challenge.

The variations in students' responses to this decentering experience are potentially connected to a few different factors. Tardy's (2015) research on genre innovation and play suggests that students have differentiated access to creativity and innovation in traditional academic genres, and that this access relates to students' privileged access to symbolic capital and the "right to bend generic convention" (p. 36). It is possible that a sense of security in this realm transfers to a willingness to play and experiment in DWPs. Interestingly, Gonzales' (2015) comparison of L1 and L2 writers finds that not having social capital in English language contexts can cause L2 students to feel more at home with unconventional and multimodal forms of expression, while L1 students tend to experience difficulty stepping into what Tardy (2015) describes as a "bewildering" (p. 153) space of DWPs without stable conventions within which to innovate.

Bandura's theory of self-efficacy is helpful in to understanding the affective responses to unfamiliar DWPs, although the role of self-efficacy beliefs in determining students' affective responses to DWPs does not appear to have been studied. Bandura (2001) describes efficacy beliefs as the most "central or pervasive" in human behaviour and the "foundation of human agency" (p. 270). He explains that individuals' beliefs in their ability to "exert control over their level of functioning and 
Volume 30, 2020

http://journals.sfu.ca/cjsdw

events that affect their lives" (p. 270) is central to their incentive to act "self-enhancingly or selfdebilitatingly," to persevere and draw on resilience through challenges, and to recognize their accomplishments. To be competent in a task requires both the skills required of the task, as well as the confidence in one's own capabilities to employ these skills well. Taken together, fostering self-efficacy beliefs is crucial to every productive context of work and learning, and supporting student efficacy beliefs across assignment types is important because writers "may not judge themselves efficacious across all types of language arts activities or even across all types of writing" (Pajares, 2003, p. 142). Writer and writing self-efficacy "makes an independent contribution to the prediction of writing outcomes" (Pajares, p. 142); at the same time, self-efficacy can help to mitigate the negative effects writers feel towards their ability to complete tasks competently (Pajares, pp. 145-46).

Writing tutors will benefit from developing strategies that foster self-efficacious beliefs among students tasked with DWPs. Bandura (2001) theorizes three contributing factors to greater self-efficacy beliefs, all of which should be possible for students to experience at the writing centre. The most prevalent factor already consistently presents across writing centre pedagogy (though the least effective for fostering self-efficacy) Bandura calls "social persuasion," which involves conversation that encourages student writers to persevere even when the writing gets tough. The other two factors are theorized as more powerfully persuasive, and yet might be less consistent across writing centre programming. They include what Bandura calls social models-observing people perceived as similar achieving success through hard work-and mastery experiences-successes achieved through perseverant behaviour (p. 289). Given the nature of these two factors in developing self-efficacious beliefs, writing centres may consider the value of programming that brings writers together in a program where they can write alongside each other, swap writing experiences, and provide peer-to-peer community support. In the context of DWPs, this would require a community writing space equipped with digital writing tools.

\section{Workshop participant questions about writing tutoring space and DWPs}

\section{On the (re)design of space and programming}

- What tutoring strategies do the configurations of our tutoring spaces enable and constrain our tutoring?

- How might other students and tutors working in this space be impacted by the demands of 
Volume 30, 2020

http://journals.sfu.ca/cjsdw

working on this multimodal digital project?

Questions emerging during our workshop suggest that while DWPs do not necessarily change the nature of our work, they do require an investment of energy in (re)developing or "tooling up" our tutoring approaches, programs, resources, and spaces. What is evident from participants' descriptions of the designs their own writing centres is that their spaces are ill-equipped to support Clare's podcasting assignment. Participants wanted to be able to record and listen to sections of Clare's draft, to call up exemplary podcasts to compare to the instructor's expectations, and to play with software to ensure that Clare's belief in her ability to complete the assignment would be sufficient enough to allow her to commit to the project. None of the workshop participants felt that their space facilitated these activities. Their spaces did not tend to have: computers set up for collaborative writing and interaction; recording software like Audacity or hardware like microphones and headphones; or the recording and listening space conducive to production.

Writing centre design often reflects the prevailing notion that writing centres are places where writing is talked about, but not done. In this way, writing centres can be transactional places that ignore the embodied experience of in-situ writing. Multimodal digital writing challenges the wisdom of transactional tutoring programs because it involves composing practices that emphasize the relational, material, and embodied experiences of writing. It also calls upon writers to use design thinking as they draw on available resources to (re)invent through tinkering and playful experimentation. Carpenter and Apostel (2017) explain that writing centres can facilitate experimentation by providing (colourful, non-institutional) studio space where students can produce through interactions with high- and low-tech tools, objects, and artifacts. For Carpenter and Apostel, students who work on DWPs need to engage in a playful multimodal invention process using "remixed combinations of words, images, text, sound, and, at times, texture" (n.p.).

Encouraging students to don this sort of design thinking mindset, in and through which they may discover the affordances of multiple communication modes and media, requires an existentially lowpressure writing space, a liminal space for moments of in-between stages of writing when writers have moved beyond what they already know but have yet to fully realize something new. The sort of "tooled-up" (Bell \& Hotson, forthcoming) invention required for DWPs calls us to encourage a liminality, so that, in safety, students can enter into chaos and failure, playfulness, and experimentation. Within such a liminal spatiality, the writing centre's role may very well be to help students experiment with writing with and inside of DWPs through mentorship that encourages recursivity-in the 
Volume 30, 2020

http://journals.sfu.ca/cjsdw

case of the hypothetical workshop podcast assignment, to use recording software throughout the process of invention-as well as spaces that encourage creativity and play. Students need support in using digital writing tools and materials to invent and produce meaning.

Supporting digital writers by asking them to attend to the locations, atmospheres, and situations that inform their composing process is also important because so much of today's digital writing is done in cafés, on trains, and school hallways on any number of mobile devices from laptops and tablets to phones and even portable gaming systems. Students take their embodied anxieties about their writing - their stuck places - with them as they move within and through their lived spaces (see Ellsworth, 1997). We hear about this in the centre when our students tell us where they were when they composed the draft we're looking at-the breakroom at their part-time job on their phone, the chair in a family member's hospital room on their tablet, the lecture by a professor for another course altogether on their laptop. Helping students attend to these situated and embodied aspects of their composing process is important because they are agentive contributors to the text being composed. Ehret and Hollett (2014) study the ways writers' "feeling bodies influence meaning-making" as they move through space and time encountering "boundaries of place, setting, activity, genre, and the like" (p. 430) as well as the affordances and constraints of mobile digital writing tools, or what Ehret and Hollett call "mobile production studios" (p. 431). They prompt us to ask how a writers' production studio as well as their experience of feeling, atmosphere, social activities/engagement, boredom, frustration, might affect how and what they write, and to consider the value of developing writers' awareness of these composing influences. There are deep connections between screen and body, but everything is agentive, and we need to (and we need writers to) understand how writers' "direct perception of things in material environments affects their composing processes, and how their feeling-histories may contribute in the moment to these felt perceptions" (Ehret \& Hollett, 2014, p. 433).

Being present with students when and where they are engaging in digital writing can create opportunities for writing tutors to listen better as we help students navigate not only institutional discourses and the power differentials therein, but also the ways online environments make human society more of what it is, rather than making us better (i.e., the reality of racism and misogyny of dominant culture amplified in a digital environment), and the ways corporatized digital writing tools seek to profit from user data. For writing centres as a community within Canada, we have a responsibility and, to some extent, an accountability to use our awareness of this problematic and divisive aspect of digital writing tools to "listen, well and deeply, in space and time, to material social conditions and 
Volume 30, 2020

http://journals.sfu.ca/cjsdw

social relations" (Garcia, 2017, p. 39). In this way, through our practice and rhetoric, we can "counteract the reductionism and retrofitting of students" (p. 39). We also need to be aware of our responsibility to acknowledge how writing centers are sites of space and place, memory, meaning, and knowledge making. The opportunity is there for cultivating relationships of difference and for strategically circulating how those relationships inform our pedagogies and contribute to the (re)-making of our centers (Garcia, 2017, p. 39).

When we begin to think in and through the racial, classist, and gendered problematics connected to both DWPs and institutions of higher education, space and technology become major constraints on our work. Who is invited into our spaces? Who are these spaces safe for? Who has access to these tools? What are the costs of access? What are we, as institutions, gaining and condoning for the use of corporatized and capitalized data-driven digital tools? We need to be aware of these aspects while we reflect on our intentionality regarding programming that supports multimodal and digital composing practices.

\section{Conclusion}

In 2009, Grutsch McKinney wrote,

It strikes me that writing center studies is at a crossroads, a moment in time where tough decisions regarding the scope of our practices need to be made... Writing has evolved with new composing technologies and media, and we must evolve, too, because we are in the writing business. A radical shift in the way that writers communicate...necessitates a radical re-imagining and reunderstanding of our practices, purposes, and goals. (p. 49)

In the decade since this statement, research on multimodal composing and DWPs has demonstrated the need for the development of practices based in digital writing pedagogies and rhetorical processes. Such pedagogies and rhetorics include tutoring strategies, programs of writing support, and facilities intentionally designed to support digital writers who are developing not just technical know-how but also multimodal literacies that involve new forms of rhetorical and design savvy as well as self-efficacy beliefs. Importantly, all of these occur within assignments that are often experimental with ambiguous expectations and assessment criteria as well as the pressure of public-facing publication. If writing teachers fail to expand our understandings of literacy and rhetorical consider- 
Volume 30, 2020

http://journals.sfu.ca/cjsdw

ations to incorporate digital composing practices, argues Selfe (2004), "we not only abdicate a professional responsibility... but we also run the risk of our curriculum holding declining relevance for students" (in Sheppard, 2009, p. 129). Employers, workplaces, and civic engagement all increasingly require participants to possess abilities to communicate effectively in and through a multitude of digital means. We have an obligation to help students use digital and multimodal composing contexts to invent, produce, and make meaning. This involves supporting students' "robust multimodal writing development" (Silver, 2019) that will prepare them to interact successfully in all these arenas (Arola, Ball, \& Sheppard, 2014, n.p.).

For Canadian writing centre professionals, this work of begins with a greater commitment and attention to DWPs, even if we are not seeing many of them in our current programming. There is a great deal of work to do to bring DWPs into the theoretical and practical consciousness of Canadian writing centres. This work involves understanding and developing strategies for attending to:

- Rethinking basic, entrenched tutoring routines, such as recognizing HOCs and LOCs;

- Shifting and directing student writing habits to engagement in design thinking and to take advantage of affordances of multiple media and modalities at their disposal in DWPs;

- Realizing affective experiences of DWPs and digital production, and what those experiences do to student self-efficacy beliefs; and

- Considering re-designs of both writing centre spaces and programming.

Writing centres may consider beginning this work with a cross-campus faculty survey to discover the number and types of DWPs being assigned to students. This effort can help writing centre professionals gather sample assignments around which to engage with these areas of concern, build professional development activities, and plan for the development of resources and programs to support DWPs. This effort may also have the benefit of establishing productive relationships with faculty who assign DWPs. Initial resource development limited to specific course projects might result in high usage numbers without the need for investments in marketing or centre rebranding. These efforts, though modest, can initiate the work of designing intentional programming, training, and hiring to support the digital and multimodal realities of today's creative, professional, and scholarly contexts of writing. 
Volume 30, 2020

http://journals.sfu.ca/cjsdw

\section{References}

Ambrosh, K., Rowe, M., Abreu, B. De, Tomè, V., Hoechsmann, M., Gutièrez-Martin, A., ... Ricco, M. Di. (2018). Praxis \& partnerships: 2nd International Media Literacy Research Symposium. The Journal of Media Literacy, 65(1-2).

Arola, K. L., Ball, C. E., \& Sheppard, J. (2014). Multimodality as a frame for individual and institutional change. Hybrid Pedagogy. Retrieved from https://hybridpedagogy.org/multimodalityframe-individual-institutional-change/

Arroyo, S. J. (2013). Participatory composition: Video culture, writing, and electracy. SIU Press.

Bandura, A. (2001). Social cognitive theory of mass communication. Media Psychology, 3, 265-299.

Bell, S. (2017). High impact creative pedagogy using a maker model of composition. Journal of Faculty Development, 31(1), 19-24.

Bell, S. (2019). Learner-created podcasts: Fostering information literacies in a writing course. Canadian Journal for Studies in Discourse and Writing/Rédactologie, 29, 51-63.

Bell, S., \& Hotson, B. (forthcoming). Defining our digital identities. WLN: A Journal of Writing Center Scholarship.

Bennett, S., Maton, K., \& Kervin, L. (2008). The "digital natives" debate: A critical review of the evidence. British Journal of Educational Technology, 39(5), 775-786. https://doi.org/10.1111/j.1467-8535.2007.00793.x

Carpenter, R., \& Apostel, S. (2017). Chapter 6: A space to play, a space to compose: A model for creative collaborations and composition practices. In P. James \& D.N. DeVoss (Eds.), Making space: Writing instruction, infrastructure, and multiliteracies. Ann Arbor, MI: University of Michigan Press. Retrieved from https://quod.lib.umich.edu/d/drc/mpub7820727/1:2/--making-spacewriting-instruction-infrastructure?g=dculture;rgn=div1;view=fulltext;xc=1

Ehret, C., \& Hollett, T. (2014). Embodied composition in real virtualities: Adolescents' literacy practices and felt experiences moving with digital, mobile devices in school. Research in the Teaching of English, 48(4), 428-452.

Ellsworth, E. A. (1997). Teaching positions: Difference, pedagogy, and the power of address. New York: Teachers College.

Garcia, R. (2017). Unmaking gringo-centers. The Writing Center Journal, 36(1), 29-60. 
Volume 30, 2020

http://journals.sfu.ca/cjsdw

Gonzales, A. L., Calarco, J. M., \& Lynch, T. K. (2018). Technology problems and student achievement gaps: A validation and extension of the technology maintenance construct. Communication Research, (August), 1-8. https://doi.org/10.1177/0093650218796366

Gonzales, L. (2015). Multimodality, translingualism, and rhetorical genre studies. Composition Forum, 31. Retrieved from https://files.eric.ed.gov/fulltext/EJ1061559.pdf

Grutsch McKinney, J. (2009). New media matters: Tutoring in the late age of print. The Writing Center Journal, 29(2), 28-51.

Helsper, E. J., \& Eynon, R. (2010). Digital natives: Where is the evidence? British Educational Research Journal, 36(3), 503-520. https://doi.org/10.1080/01411920902989227

Judd, T. (2018). The rise and fall (?) of the digital natives. Australasian Journal of Educational Technology, 34(5), 99-119. https://doi.org/AE 2013029

Kent-Drury, R. (1998). Finding a place to stand: Negotiating the spatial configuration of the networked computer classroom. Computers and Composition, 15(3), 387-407.

Lunsford, A., \& Ede, L. (2009). Among the audience: On audience in an age of new literacies. In M. Elizabeth Weiser et al., (Eds.), Engaging audience: Writing in an age of new literacies (pp. 42-69). National Council of Teachers of English.

McLeod, S. (1991). The affective domain and the writing process: Working definitions. Journal of Advanced Composition, 38(4), 96-105.

Mills, K., Comber, B., \& Kelly, P. (2013). Sensing place: Embodiment, sensoriality, kinesis, and children behind the camera. English Teaching, 12(2), 11-27.

Mills, K. A., \& Doyle, K. (2019). Visual arts: a multimodal language for Indigenous education. Language and Education, 33(6), 521-543. https://doi.org/10.1080/09500782.2019.1635618

Pajares, F. (2003). Self-efficacy beliefs, motivation, and achievement in writing: A review of the literature. Reading \& Writing Quarterly, 19, 139-158.

Passanisi, J., \& Peters, S. (2012). Being a digital native isn't enough. Scientific American. Retrieved from: https://blogs.scientificamerican.com/guest-blog/being-a-digital-native-isnt-enough/

Prensky, M. (2001). Digital natives, digital immigrants Part 1. On the horizon: The strategic planning resource for education professionals, 9(5), 1-6. https://doi.org/10.1108/10748120110424816

Purdy, J. (2014). What can design thinking offer writing studies? College Composition and Communication, 65(4), 612-641. 
Volume 30, 2020

http://journals.sfu.ca/cjsdw

Sabatino, L. A. (2019). Introduction: Design theory and multimodal composing. In L.A. Sabatino \& B. Fallon, B. (Eds.), Multimodal composing: Strategies for twenty-first-century writing consultations (pp. 3-22). Logan: Utah State University Press.

Sabatino, L. A., \& Fallon, B. (2019). Multimodal composing: Strategies for twenty-first-century writing consultations. Logan: Utah State University Press.

Sheppard, J. (2009). The rhetorical work of multimedia production practices: It's more than just technical skill. Computers and Composition, 26, 122-131.

Silver, N. (2019). "My writing writing”: Student conceptions of writing and self-perceptions of multimodal compositional development. In A.R. Gere (Ed.), Developing writers in higher education: A longitudinal study (pp. 217-246). University of Michigan Press, Digitalculturebooks.

Soja, E. W. (2010). Seeking spatial justice. Minneapolis: University of Minnesota Press.

Tardy, C. (2015). Beyond convention: Genre innovation in academic writing. University of Michigan UP.

Wargo, J. M. (2018). Writing with wearables? Young children's intra-active authoring and the sounds of emplaced invention. Journal of Literacy Research, 50(4), 502-523. 
Volume 30, 2020

http://journals.sfu.ca/cjsdw

\section{Appendix A: Tutoring Space Configurations}

Map A: Individual office

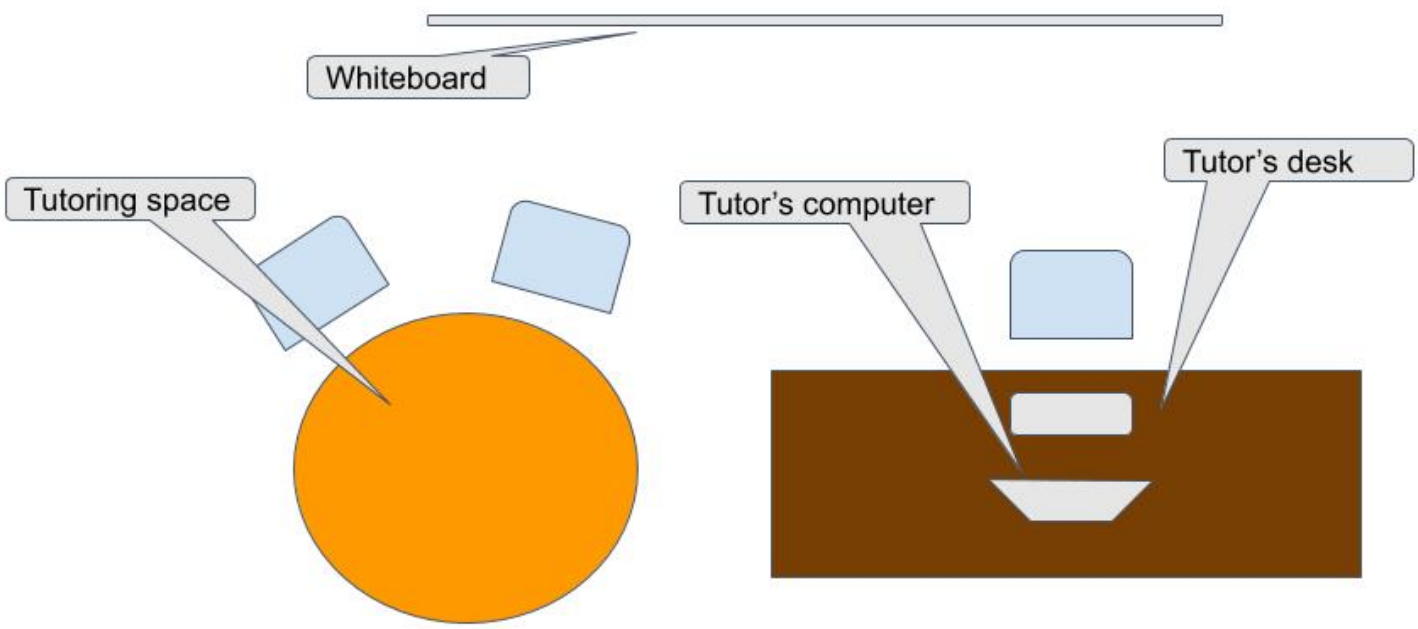

Map B: Small Media Space




Volume 30, 2020

http://journals.sfu.ca/cjsdw

Map C: Tech-table with multipledevice connection

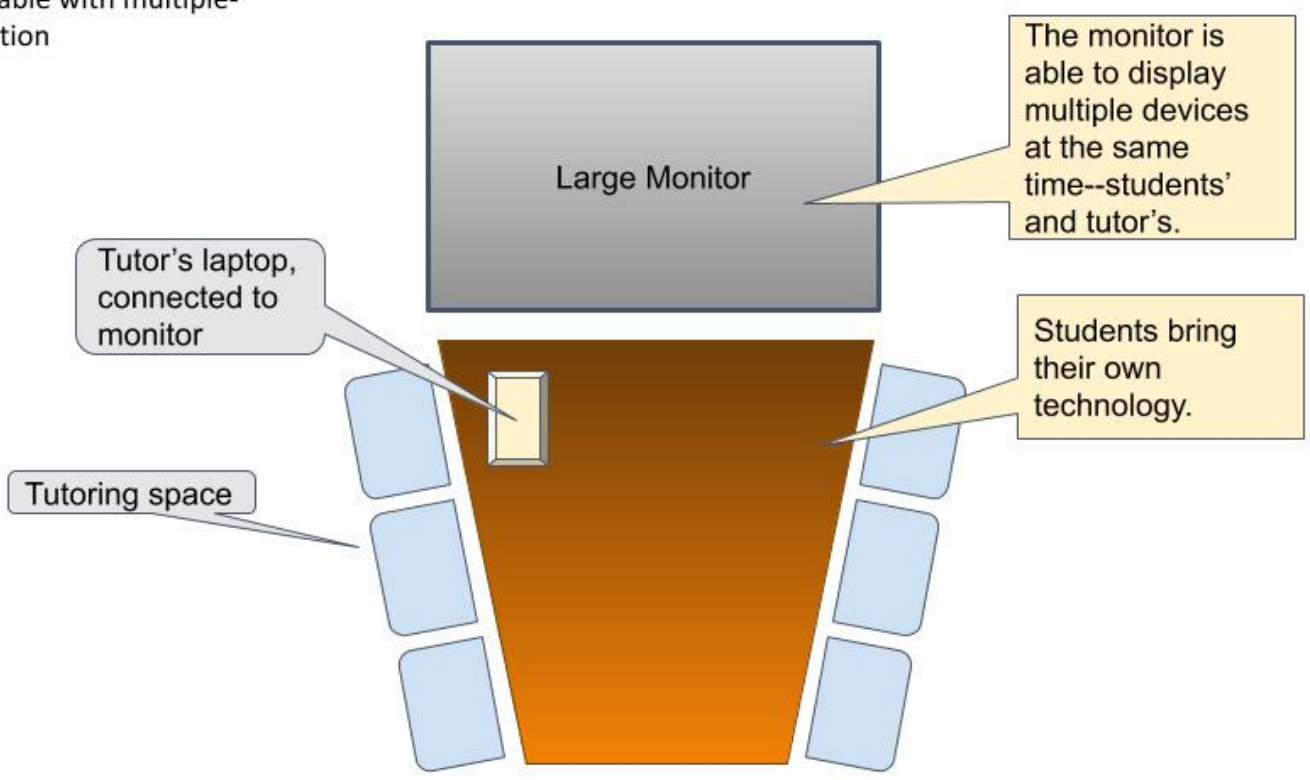

Map D: Open Concept
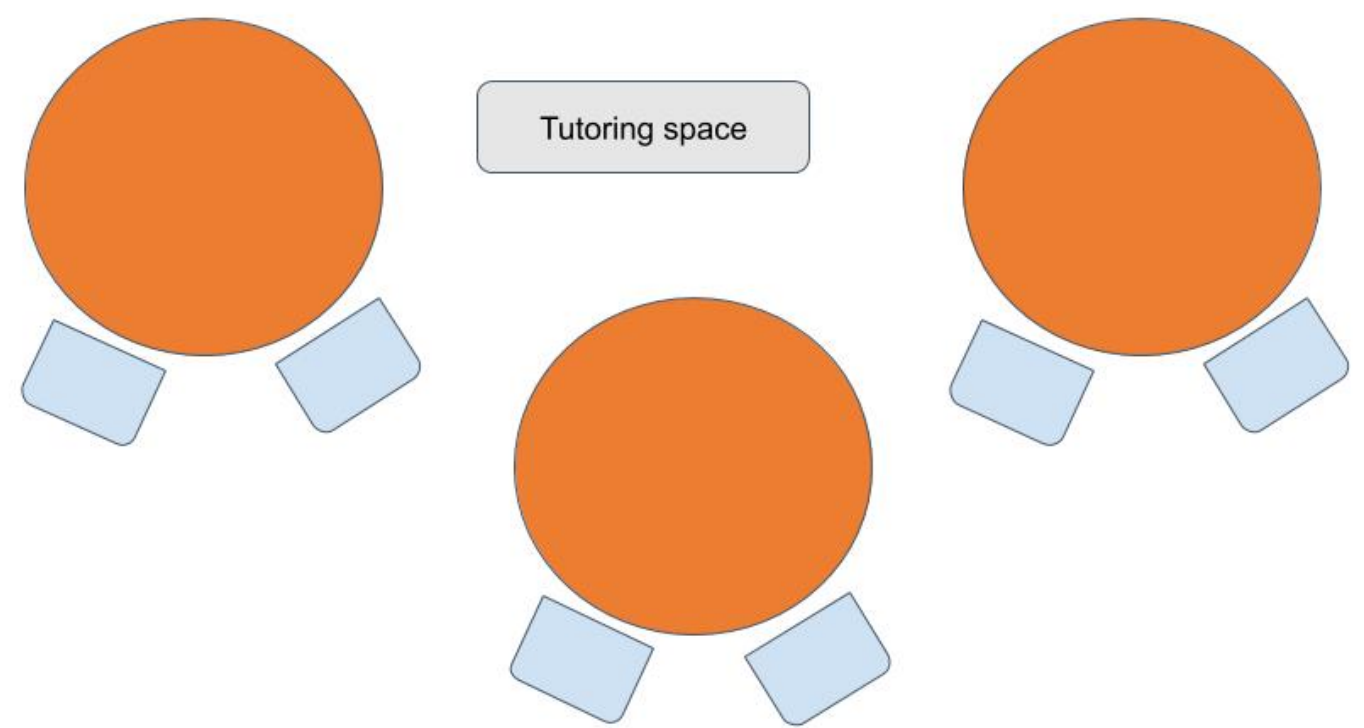
Volume 30, 2020

http://journals.sfu.ca/cjsdw


Tutoring space
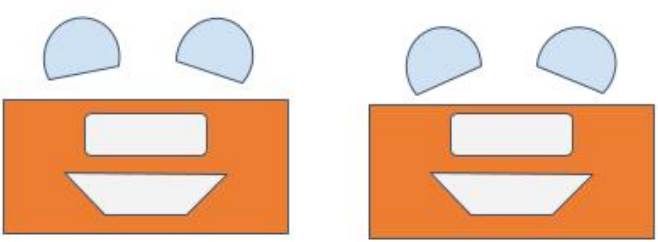
Volume 30, 2020

http://journals.sfu.ca/cjsdw

\section{Appendix B: Assignment scenario}

Social Science 1000: Mid-term Assignment

In a 15-minute audio recording (.mp3) + written transcript posted to the course blog:

1. Explain the concept "ideology" by analyzing an advertisement (see list of approved ads).

2. Illustrate the ways capitalism operates on constructed notions of what's "normal, natural, and necessary."

Explain clearly enough to make these ideas understandable to a peer.

Have a clear thesis statement that answers a "so what" question. Have fun with it! Your goal is to make these ideas clear and compelling to a peer. Your podcast should be somewhere between formal and informal and can be creative.

Engage with two course readings and additional resources (popular or scholarly) to interrogate the advertisement's claims about the product .

Clare's chosen ad:

(IMAGE: https://i.pinimg.com/originals/ea/6e/98/ea6e9885d961f40174a827dd103ec9c3.jpg)

[Image of a Got Milk? print advertisement with a super hero, in a dramatic pose, with his fist on the ground. A glass of milk is near his fist. The super hero has milk above his upper lip.]

\section{Clare's draft:}

According to the Webster's Dictionary, capitalism is an economic system built on the notion of a free market. Fair competition in this free market, it is thought, makes capitalism an effective economic model (lecture slides week 4). Advertising is one of the ways to compete in the free market because it helps companies to show that their products exist, and that they are needed. When people see advertisements for products that they need, they are likely to buy them (lecture slides week 6). One of the most well-known and iconic advertising campaigns now studied because of its success was the got milk campaign most memorable for featuring a variety of well-known celebrities and athletes all 
Volume 30, 2020

http://journals.sfu.ca/cjsdw

wearing white milk moustaches (gotmilk.com). Many of them have messages about the benefits of drinking milk, from quenching thirst to having strong bones. The got milk advertisement campaign uses ideology to sell milk, and it is an example of how capitalism operates on constructed notions of what's "normal, natural, and necessary."

The successful ad campaign first launched in 1993 and ran until 2014 when dairy advertising changed to address competing non-dairy milks ("got milk"). Some of the more extreme and controversial got milk ads featured violent situations ("got milk"). For example, in one ad a person is killed in a car accident and finds himself in hell because there is no milk to wash down an endless afterlife of cookies. Another violent got milk ad features an old man whose arms fall off because he doesn't drink enough milk. The children in the ad who see this instantly start drinking as much milk as they can despite previously not wanting to. Many of the most recent got milk ads hit home this message of milk's health benefits because of increasing competition from non-dairy milks, which tend to focus on health claims ("got milk"). For example, the got milk ad that features superman with the ideological message that "even kryptonians drink milk to stay strong" does this.

Ideology is present in "beliefs that are understood to be normal, natural, and necessary," and this is evident in the Got Milk advertising campaign (Lecture slides 5). Milk is healthy because it is calciumrich and full of nutrients. Therefore, it is important for humans to consume it regularly both as children and adults for normal growth and to prevent diseases like osteoporosis (dairy.org). Milk is a human need, according to the advertisement. Superman helps remind us of this in his Got Milk ad. In this ad, superman looks like he's just landed because his red cape is floating around him like red muscles that we know make him strong. He has a very serious and intense look, which contrasts with his milk moustache, which is sort of silly. One of his fists is punching the ground right beside the glass of milk he must have just had a drink of. He is a very strong and formidable figure. Everything about the ad says strength, from the tendons of his flowing red cape to his shapely figure. The message is that milk gives him his muscles and strength. In this way, the notion that milk makes you strong is effectively constructed through this visual depiction of superman. Advertisements like this one use "metaphor and visual imagery to construct arguments and connotative meaning" (Lecture slides 2). 